\title{
Up-regulation of microRNAs, miR21 and miR23a in human liver cancer cells treated with Coptidis rhizoma aqueous extract
}

\author{
MEIFEN ZHU ${ }^{1}$, NING WANG $^{1}$, SAI-WAH TSAO ${ }^{2}$, MAN-FUNG YUEN $^{4}$, YIGANG FENG $^{6}$, \\ THOMAS S.K. WAN ${ }^{5}$, KWAN MAN ${ }^{3}$ and YIBIN FENG ${ }^{1}$ \\ ${ }^{1}$ School of Chinese Medicine; Departments of ${ }^{2}$ Anatomy, and ${ }^{3}$ Surgery, The University of Hong Kong; \\ Departments of ${ }^{4}$ Medicine, and ${ }^{5}$ Pathology, The University of Hong Kong, Queen Mary Hospital, Hong Kong, SAR; \\ ${ }^{6}$ Guanghua School of Stomatology, Sun Yat-Sen University, Guangzhou, P.R. China
}

Received August 20, 2010; Accepted November 1, 2010

DOI: $10.3892 / \mathrm{etm} .2010 .164$

\begin{abstract}
Coptidis rhizoma (CR; Huanglian in Chinese) has been used for the treatment of cancer in Chinese medicine, and recent studies have supported its use in cancer therapy. MicroRNAs (miRNAs) play an important role in the pathophysiology of human cancers. We examined alterations in the miRNA profile of hepatocellular carcinoma (HCC) cells after treatment with Coptidis rhizoma aqueous extract (CRAE). An on-chip microarray method was used to detect alterations in the expression profile of miRNAs in human HCC MHCC97-L cells after exposure to $175 \mu \mathrm{g} / \mathrm{ml} \mathrm{CRAE}$. Altered expression of several miRNAs was detected in the MHCC97-L cells after treatment with $175 \mu \mathrm{g} / \mathrm{ml}$ CRAE. The microarray results were validated by quantitative real-time PCR (qRT-PCR). Consistent results were obtained; qRT-PCR confirmed that both miR-21 and miR-23a were significantly up-regulated. TargetScan and PicTar microRNA databases were used to predict the possible target genes of the altered miRNAs. The results showed that the altered miRNAs after CRAE treatment may serve as markers for the therapy of liver cancer. To the best of our knowledge, this is the first report on the up-regulation of miRNAs, miR21 and miR23a in human liver cancer cells treated with CRAE. Our results suggest that CRAE targets miR-21 and miR-23a in liver cancer cells supporting the potential application of CRAE in the treatment of HCC.
\end{abstract}

\section{Introduction}

Hepatocellular carcinoma (HCC) is associated with a dismal patient outcome, and its incidence rate continues to rise (1).

Correspondence to: Dr Yibin Feng, School of Chinese Medicine, The University of Hong Kong, 10 Sassoon Road, Hong Kong, SAR, P.R. China

E-mail: yfeng@hku.hk

Key words: Coptidis rhizoma aqueous extract, microRNA, hepatocellular carcinoma, miR-21, miR-23a
At present, only $10-20 \%$ of patients with HCC are eligible for surgical therapy (2). The results of therapeutic treatment for liver cancer remain unsatisfactory.

MicroRNAs (miRNAs) are single-stranded RNA molecules, approximately 21-23 nucleotides in length, which are able to regulate gene expression at either the transcriptional or post-transcriptional level. miRNAs are encoded by genes that are transcribed from DNA, but are not translated into protein. This type of non-coding RNA was first described in 1993 by Lee et al (3), which was later referred to as microRNA (4). Subsequent studies in recent years have demonstrated a significant difference in miRNA expression profiles in human malignancies, including chronic lymphocytic leukaemia, pediatric Burkitt's lymphoma, gastric cancer, lung cancer and large-cell lymphoma. These findings suggest that miRNAs may play an important role in carcinogenesis as a novel class of oncogenes or tumor-suppressor genes $(5,6)$. Thus, miRNAs have been considered as novel targets for cancer therapy.

Coptidis rhizoma (CR) has been used in Chinese medicine for thousands of years. Previous studies have demonstrated that CR exhibits a variety of pharmacological actions, including anti-neoplastic, anti-oxidative, anti-bacterial, anti-viral, antiinflammatory, anti-hyperglycemic, anti-hypertensive and liver protective effects (7-9). The anti-tumor action of CR has been extensively reported. CR induces multiple signal transduction pathways to promote cancer cell apoptosis, inhibiting tumor cell proliferation and neoplastic angiogenesis. Yet, few studies have reported the effects of CR in the treatment of liver cancer $(10,11)$.

In the present study, we used a sensitive miRNA on-chip array to examine the alteration in the miRNA expression profile in HCC MHHCC-97 cells after treatment with Coptidis rhizoma aqueous extract (CRAE). In the miRNA on-chip array, the elevated expression of miR-21 and miR-23a was detected in the MHCC97-L cells after treatment with $175 \mu \mathrm{g} /$ $\mathrm{ml}$ of CRAE. The altered expression of these miRNAs was further validated by quantitative real-time PCR (qRT-PCR) analysis. Using TargetScan and PicTar databases, analysis indicated that several signal transduction pathways may be altered by CRAE via miRNA expression. Our results suggest the therapeutic potential of CRAE by targeting specific miRNAs in liver cancer cells. 


\section{Materials and methods}

Preparation of the Coptidis rhizoma aqueous extract. To prepare the CRAE, raw material was cut into small pieces, and $50 \mathrm{~g}$ of crude $\mathrm{CR}$ was boiled in distilled (10 times) water $(\mathrm{w} / \mathrm{v})$ at $100^{\circ} \mathrm{C}$ for $1 \mathrm{~h}$ and then filtered. Next, the filtrate was evaporated to dryness, and the residue was dissolved in water containing $0.1 \%$ dimethyl sulfoxide (DMSO). The quality control of CRAE was reported in our previous study (9).

Cell culture and drug intervention. Human HCC MHCC97-L cells were maintained in high glucose Dulbecco's modified Eagle's medium (Invitrogen, USA) supplemented with $10 \%$ fetal bovine serum and $1 \%$ antibiotics. Cells were incubated in a humidified incubator containing $5 \% \mathrm{CO}_{2}$ at $37^{\circ} \mathrm{C}$. For drug intervention, cells were seeded in T25 culture flasks with $\sim 70 \%$ confluence. Cells were starved overnight in serum-free medium and then were exposed to $175 \mu \mathrm{g} / \mathrm{ml}$ of CRAE for $48 \mathrm{~h}$. Then, the cells were collected for analysis using cell scrappers. Cells treated with vehicle (0.1\% DMSO) for $48 \mathrm{~h}$ were collected as the control.

Cell viability assay. The MTT assay was used to determine the cytotoxicity of CRAE in the MHCC97-L cells. Cells were seeded in a 96-well plate at a density of 10,000 cells per well, and a series of concentrations $(0,1.75,3.5,7,14,28,56,112$, 224 and $448 \mu \mathrm{g} / \mathrm{ml}$ ) of CRAE were added to the cells after a 48-h incubation with the control 0.1\% DMSO. Fifteen microliters of 3-(4,5-dimethylthiazol-2-yl)-2,5-diphenyltetrazolium bromide (MTT; $5 \mathrm{mg} / \mathrm{ml}$; Sigma, USA) was added to each well, and the cells were further incubated at $37^{\circ} \mathrm{C}$ for $4 \mathrm{~h}$. The culture medium was then discarded, and $200 \mu \mathrm{l}$ DMSO was added to dissolve the crystals. The Multiskan MS microplate reader (Labsystems, Finland) was used to measure the absorbance of formazan formed at $595 \mathrm{~nm}$.

Preparation of the miRNA-enriched total RNA sample. miRNA-enriched total RNAs of MHCC97-L cells untreated and treated with $175 \mu \mathrm{g} / \mathrm{ml}$ CRAE were extracted and purified by the miRNeasy Mini kit (Qiagen, Germany) according to the manufacturer's instructions.

On-chip microarray analysis. The NCode ${ }^{\mathrm{TM}}$ Rapid miRNA Labeling System (Invitrogen) was used for Poly (A) tailing of total RNA and ligation for on-chip microarray analysis. Briefly, $1 \mu \mathrm{l}$ of $\mathrm{NCode}^{\mathrm{TM}}$ Multi-Species miRNA microarray controls $(2 \mathrm{fmol} / \mu \mathrm{l})$ was spiked, and Poly (A) tailing reactions were set up for each total RNA sample. The Poly (A) tailed reactions were separately ligated to the labeled DNA polymers using the 6X Alexa Fluor ${ }^{\circledR} 3$ (A3) Rapid Ligation mix or 6X Alexa Fluor ${ }^{\circledR} 5$ (A5) Rapid Ligation mix, according to the manufacturer's instructions. For hybridization of the labeled miRNAs with the miRNA microarray, the two differentially labeled reactions were combined into one tube, and the volume was reduced by half in a SpeedVac ${ }^{\circledR}$ Concentrator. BSA $(50 \mathrm{mg} / \mathrm{ml})$ was then added to a total volume of $28.5 \mu \mathrm{l}$. The samples were incubated with $28.5 \mu \mathrm{l}$ of $2 \mathrm{X}$ enhanced hybridization buffer at $65^{\circ} \mathrm{C}$ for $10 \mathrm{~min}$ and then loaded onto NCode $^{\mathrm{TM}}$ Human miRNA Microarrays V3. The arrays were mounted with the Maui Mixer SL and hybridized overnight
(16-20 h) at $52^{\circ} \mathrm{C}$ with constant mixing. The arrays were then washed according to the standard protocol recommended by the manufacturer. The arrays were scanned using a GenePix $^{\circledR}$ 4000B microarray scanner (Molecular Devices, USA). Alexa Fluor ${ }^{\circledR} 3$ (green channel) and Alexa Fluor ${ }^{\circledR} 5$ (red channel) excitation and emission maxima were identical to Alexa Fluor ${ }^{\circledR} 546$ and 647, respectively. The scanner was programmed accordingly at $556 \mathrm{~nm}$ (excitation) and $573 \mathrm{~nm}$ (emission) for Alexa Fluor ${ }^{\circledR} 3$, and $650 \mathrm{~nm}$ (excitation) and $665 \mathrm{~nm}$ (emission) for Alexa Fluor ${ }^{\circledR}$ 5. The scanned images were saved as TIFF files with the array barcode number included in the name of the file, then annotated and analyzed using GenePix ${ }^{\circledR}$ software with the GAL files containing the array list samples for the human samples. The data output file was saved as a GPR file and exported as a text file for easy access and analysis using Microsoft Excel.

Quantitative real-time PCR for miRNA analysis. The miRCURY LNA ${ }^{\mathrm{TM}}$ Universal RT microRNA PCR system is designed for sensitive and accurate detection of miRNA by quantitative real-time PCR using SYBR Green (Exiqon, Denmark). The miRCURY LNA Universal RT miRNA PCR portfolio is comprised of three types of reagent kits, including the Universal cDNA synthesis kit and the SYBR Green master mix kit. Single-stranded cDNA was generated from the miRNA-enriched total RNA sample by reverse transcription using the Universal cDNA synthesis kit according to the manufacturer's instructions. The expression of the miRNAs was detected using the SYBR Green master mix kit in a 96-well optical plate. Finally, relative miRNA expression levels were calculated by comparison to the expression of the endogenous control of U6 snRNA.

Target prediction. To predict the function of the selected miRNAs related to the anti-tumor action of CRAE, we indentified the possible targets of miR-21 and miR-23a based on two miRNA databases, TargetScan (http://www.targetscan.org/ index.html) and PicTar (http://pictar.mdc-berlin.de), according to the manufacturer's instructions. Several target genes which were common to both TargetScan and PicTar were identified for further study.

Validation of the predicted targets. To validate the predicted target genes from the two miRNA databases, RT-PCR was used to detect the expression of the predicted targets. Reversetranscription reaction was performed using the Roche Reverse Transcription kit (Roche, USA) to prepare the cDNA samples. qRT-PCR was conducted using the SYBR Green PCR kit (Roche) with $1 \mu \mathrm{M}$ of primers for PLAG1 (left: 5'-GTCCAG CCCGAAATATGAGA-3', right: 5'-CAGCACCAAGAGGCA ACC-3', Invitrogen), or RP2 (left: 5'-AAGAGACGGAAG GCTGACAA-3', right: 5'-GAACATGTAGTCTTTTGGATCA ACC-3', Invitrogen), or STAT3 (left: 5'-CCCTTGGATTGA GAGTCAAGA-3', right: 5'-AAGCGGCTATACTGCTGGTC-3', Invitrogen), or SATB1 (left: 5'-GGGTACGCGATGAACTG AA-3', right: 5'-TTCTGAAAGCAAGCCCTGA-3', Invitrogen), or NTF3 (left: 5'-AAAAACGGTTGCAGGGGTAT-3', right: 5'-GGTTTGGGATGTTTTGCACT-3', Invitrogen), or POU4F2 (left: 5'-CCCTTTGAACCCCACCTC-3', right: 5'-CTT CCTGCAAACAGCCATCT-3', Invitrogen), or NEK6 (left: 


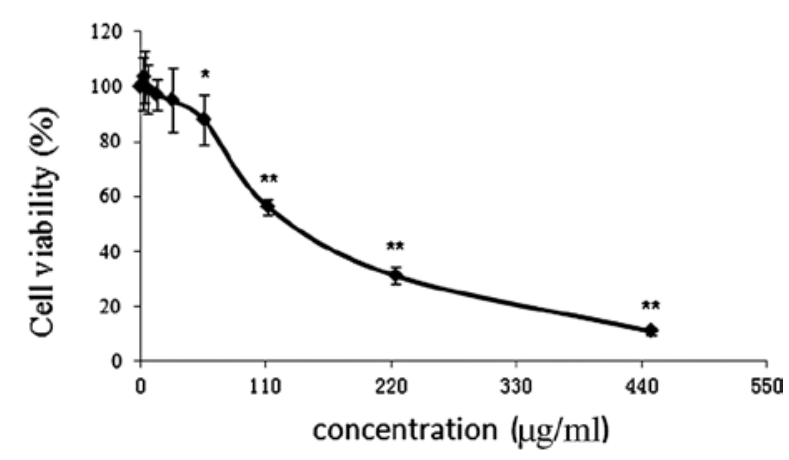

Figure 1. Cytotoxicity of CRAE in hepatocellular carcinoma MHCC97-L cells. Cells were seeded in 96-well plates at a density of 10,000 cells per well and treated with different concentrations of CRAE $(0,1.75,3.5,7,14,28,56$, 112,224 and $448 \mu \mathrm{g} / \mathrm{ml}$ ) for $48 \mathrm{~h}$. MTT assay was introduced to determine the cell viability after CRAE intervention $\left({ }^{*} \mathrm{p}<0.05,{ }^{* *} \mathrm{p}<0.01\right.$ compared to the control group).

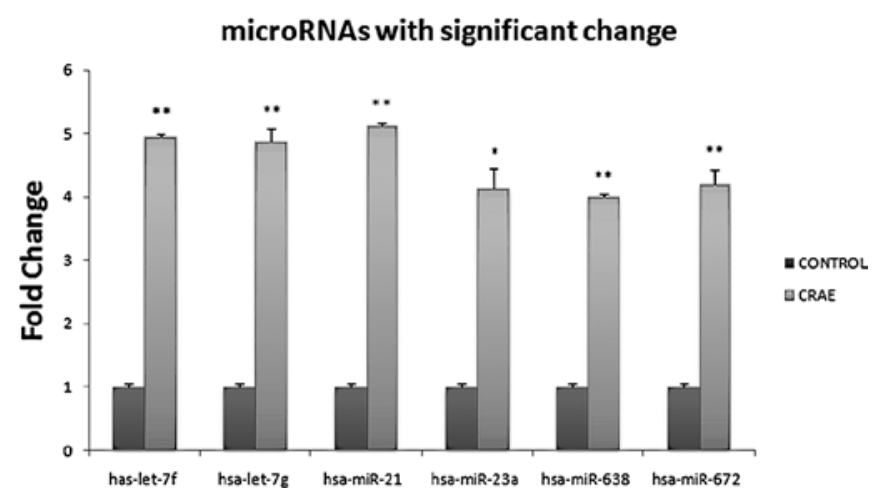

Figure 2. CRAE alters expression of miRNAs in human liver cancer. Six miRNAs, let-7f, let-7g, miR-21, miR-23a, miR-638 and miR-672, were definitely up-regulated by $175 \mu \mathrm{g} / \mathrm{ml}$ of CRAE for $48 \mathrm{~h}$ in comparison to the controls which was untreated $\left({ }^{*} \mathrm{p}<0.05,{ }^{* *} \mathrm{p}<0.01\right.$ compared to the control group).

5'-CTGGGCTGTCTGCTGTACG-3', right: 5'-AGTCACACT GCTCGATCTTCTG-3', Invitrogen), or SLC6A14 (left: 5'-AGC AAAGAGGTGGATATTCTGG-3', right: 5'-CACCAATGA CCAGATAAATATTGC-3', Invitrogen), or SET8 (left: 5'-CCA TCAAGGGCAAACAGG-3', right: 5'-GACTGCAGCTCG GCTTTG-3', Invitrogen) on the LightCycler 480 real-time PCR system (Roche). The expression of GAPDH was used as the endogenous control (forward: 5'-GCTAGGGACGGC CTGAAG-3'; reverse: 5'-GCCCAATACGACCAAATCC-3'; Invitrogen) for the normalization of gene expression of the above primers.

Statistical analysis. Statistical differences among groups were determined by the Student's t-test. Differences were considered to be significant at $\mathrm{p}<0.05$.

\section{Results}

Cytotoxicity of CRAE on HCC MHCC97-L cells. In order to determine the cytotoxicity of CRAE on MHCC97-L cells, the MTT assay was conducted to detect the cancer cell viability after CRAE intervention. A dose-dependent suppression in
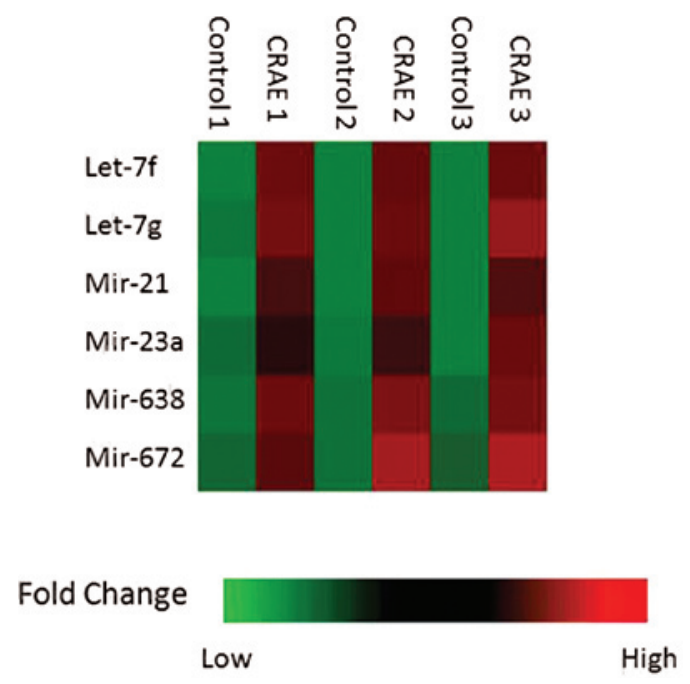

Figure 3. Quantitation of the six miRNAs which exhibited a significant change in expression after treatment with $175 \mu \mathrm{g} / \mathrm{ml}$ of CRAE. The microarray experiment used three pairs of chips: CRAE 1 (treatment with CRAE) and Control 1 (untreated), CRAE 2 and Control 2, and CRAE 3 and Control 3.

the viability of MHCC97-L cells was observed after treatment with various concentrations of CRAE for $48 \mathrm{~h}$. Since the major compound in CRAE is berberine, which was found to exhibit a potent anti-cancer effect in our previous study (11), the concentration of CRAE was normalized by the content of berberine, and the $\mathrm{IC}_{50}$ value was calculated accordingly. Our result showed that $\sim 175 \mu \mathrm{g} / \mathrm{ml}$ of CRAE was able to induce 50\% MHCC97-L cell death after a 48-h treatment, indicating that CRAE exhibits a potent anti-cancer action at a low dose (Fig. 1).

Expression of miRNA profiling in MHCC-97 cells with or without treatment of $C R A E$. In order to delineate the responses of miRNAs in the MHCC97-L cells to CRAE treatment, miRNA-enriched total RNAs were extracted from untreated MHCC97-L cells and cells treated with $175 \mu \mathrm{g} / \mathrm{ml} \mathrm{CRAE} \mathrm{for}$ $48 \mathrm{~h}$. The values for each individual miRNA probe sequence were printed in triplicates on the array. Cluster analysis was conducted on the expression profiles of the control and experimental groups. The NCode ${ }^{\mathrm{TM}}$ Human miRNA Microarray V3 chip was used. Those miRNAs which exhibited significant changes $(p<0.05)$ are shown in Fig. 2. Six miRNAs, including hsa-let-7f, hsa-let-7g, hsa-mir-21, hsa-mir-23a, hsa-mir-638 and has-mir-672, were strikingly up-regulated after $175 \mu \mathrm{g} / \mathrm{ml}$ CRAE treatment for $48 \mathrm{~h}$ as shown in Fig. 3.

Validation of the differential expression of miRNAs by $q R T-P C R$. The expression levels of the six miRNAs were determined by qRT-PCR using SYBR ${ }^{\circledR}$ Green 1 with U6 RNA as an endogenous control. The same miRNA-enriched RNAs were reversely transcribed and amplified in a 96-well plate for SYBR ${ }^{\circledR}$ Green 1 real-time PCR analysis. Among these six miRNAs, elevated expression levels of miR-21 and miR-23a after CRAE treatment were confirmed. A 3-fold up-regulation of miR-21 expression was detected in the MHCC97-L cells treated with $175 \mu \mathrm{g} / \mathrm{ml}$ CRAE in comparison to the control group (Fig. 4A). Strikingly, the transcription level of miR-23a 
Table I. Prediction of miR-21 target genes.

\begin{tabular}{lll}
\hline Target gene & Accession no. & \multicolumn{1}{c}{ Target gene name } \\
\hline PLAG1 & NM_002655 & Homo sapiens pleiomorphic adenoma gene 1 \\
RP2 & NM_006915 & Homo sapiens retinitis pigmentosa 2 (X-linked recessive) \\
STAT3 & NM_139276 & $\begin{array}{l}\text { Homo sapiens signal transducer and activator of transcription 3 } \\
\text { (acute-phase response factor) }\end{array}$ \\
SATB1 & NM_002971 & $\begin{array}{l}\text { Homo sapiens special AT-rich sequence binding protein 1 } \\
\text { (binds to nuclear matrix/scaffold-associating DNA's) }\end{array}$ \\
NTF3 & NM_002527 & Homo sapiens neurotrophin 3 \\
\hline
\end{tabular}

Table II. Prediction of miR-23a target genes.

\begin{tabular}{lll}
\hline Target gene & Accession no. & \multicolumn{1}{c}{ Target gene name } \\
\hline SEMA6D & NM_153618 & $\begin{array}{l}\text { Homo sapiens sema domain, transmembrane domain (TM), } \\
\text { and cytoplasmic domain, (semaphorin) 6D }\end{array}$ \\
POU4F2 & NM_004575 & Homo sapiens POU domain, class 4, transcription factor 2 \\
NEK6 & NM_014397 & Homo sapiens NIMA (never in mitosis gene a)-related kinase 6 \\
SLC6A14 & NM_007231 & Homo sapiens solute carrier family 6 (neurotransmitter transporter), member 14 \\
SET8 & NM_020382 & Homo sapiens PR/SET domain containing protein 8
\end{tabular}

A

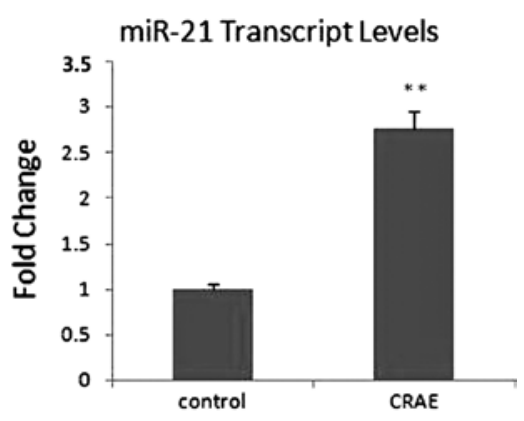

B

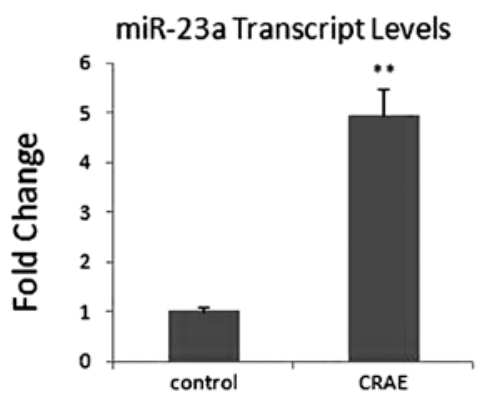

Figure 4. Validation by SYBR Green real-time PCR analysis of the two miRNAs which exhibited significant changes in expression in MHCC97-L cells after treatment with $175 \mu \mathrm{g} / \mathrm{ml} \mathrm{CRAE}$. (A) miR-21 was up-regulated by $175 \mu \mathrm{g} / \mathrm{ml}$ CRAE more than 3-fold. (B) miR-23a was up-regulated by $175 \mu \mathrm{g} /$ ml CRAE nearly 5-fold ( ${ }^{* *} \mathrm{p}<0.01$ compared to the control group).

was increased 5-fold in the MHCC97-L cells treated with CRAE (Fig. 4B). However, alteration in the expression levels of hsa-let-7f, hsa-let-7g, hsa-mir-638 and hsa-mir-672 was not confirmed in the qRT-PCR analysis. These results revealed that miR-21 and miR-23a expression was significantly up-regulated by $175 \mu \mathrm{g} / \mathrm{ml}$ CRAE treatment.
A

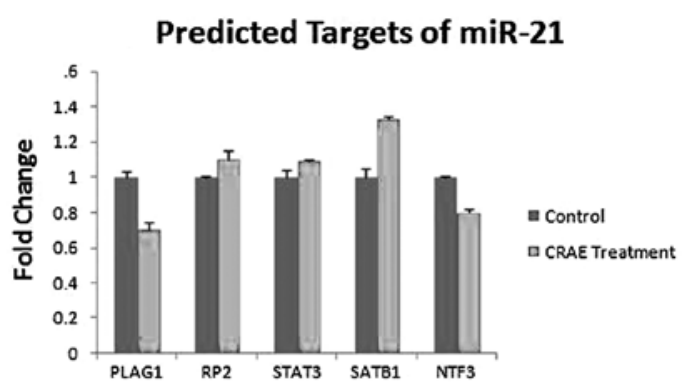

B

Predicted Targets of miR-23a

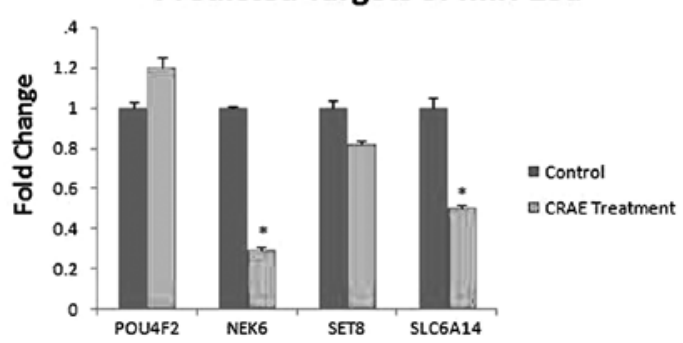

Figure 5. Validation of the predicted targets of miR-21 and miR-23a. (A) Expression of the predicted targets of miR-21. No significant change was observed after treatment with CRAE when compared to the control. (B) Expression of the predicted targets of miR-23a. Expression of NEK6 and SLC6A14 showed a significant change after treatment with CRAE when compared to the control (* $\mathrm{p}<0.05$ compared to the control group).

Prediction of potential target genes of $m i R-21$ and $m i R-23 a$. To predict the function of the selected miRNAs related to the anti-tumor action of CRAE, identification of the target genes were attempted using related miRNA databases. Two miRNA databases, TargetScan (http://www.targetscan.org/index.html) and PicTar (http://www.pictar.mdc-berlin.de), were searched 
according to the manufacturer's instructions, and several target genes which were common to both TargetScan and PicTar were identified. The most promising five candidate targets for miR-21 and miR-23a are listed in Tables I and II, respectively.

Validation of the predicted targets. The expression of PLAG1, RP2, STAT3, SATB1 and NTF3, predicted target genes of miR-21, and POU4F2, NEK6, SLC6A14 and SET8, predicted target genes of miR-23a, was determined by qRT-PCR using SYBR $^{\circledR}$ Green 1 with GAPDH as an endogenous control. We found that only the expression of NEK6 and SLC6A14 exhibited a significant change after treatment with $175 \mu \mathrm{g} / \mathrm{ml}$ CRAE, while the predicted targets of miR-21 exhibited no change (Fig. 5A and B).

\section{Discussion}

Discovered in 1993 for the first time (4), miRNA has been shown to play a crucial role in the regulation of physiological processes in cell biology $(12,13)$. Moreover, evidence supports the involvement of miRNA in the initiation and progression of human cancers. For example, miR-155 is overexpressed in breast cancer and has the potential to be a target of breast cancer therapy (14). miR-126, together with epidermal growth factor-like domain 7, inhibit proliferation in lung cancer (15). miR-15a and miR-16 are underexpressed in ovarian cancer by down-regulating the expression of bim-1 (16). Bhattacharyya et al (17) compared the levels of miRNA in tumor cells and adjacent non-tumor cells from liver cancer patients with a history of hepatitis. They reported that patients with poor disease-free survival had low overall levels of 19 particular miRNAs compared to those showing better survival after 16 years of follow-up. A unique pattern of miRNA expression is found in different hematopoietic cell lineages and plays a role in their proliferation and differentiation (17). All the currently available data confirm the involvement of miRNAs in cancer progression and demonstrate the potential of miRNAs as markers for diagnosis, prognosis and perspective treatment targets for cancer therapy.

Medicinal plants have had an extensive history of use in cancer therapy, and plant-derived compounds have played an important role in the development of various clinically useful anti-cancer agents $(18,19)$. Coptidis rhizoma (CR) is a species of goldthread native to China (Botanical Dermatology Database; http://bodd.cf.ac.uk) and one of the 50 fundamental herbs used in traditional Chinese medicine (20). It has been shown that CR is a promising Chinese herb used in cancer therapy; however, comprehensive studies on the molecular mechanism of the anti-tumor action of CRAE are limited $(10,21)$. We previously reported that CR had the strongest cytotoxicity among a selection of 16 anti-cancer Chinese herbs in rat leukemia L-1210 cells, and a much higher inhibitory activity for growth of tumor cells was present in the water extract of $\mathrm{CR}$, compared to extracts using other solvents (22). Our previous studies revealed that CRAE and its active compound, berberine, are promising anti-cancer drugs due to their low toxicity and liver protective properties $(9-11,18,21)$. In the present study, we confirmed that regulation of certain specific miRNAs may also contribute to an anti-cancer effect $(23,24)$. The microarray results revealed a differential expres- sion profile for various miRNAs between cells treated with and without CRAE. The six potential miRNAs were further evaluated by qRT-PCR, indicating that CRAE treatment up-regulates the expression of miR-21 and miR-23a. Previous reports have revealed that miRNA expression profiles are influenced by the intervention of natural products isolated from medicinal plants, such as curcumin (25), isoflavone (26), indole-3-carbinol, 3,3'-diindolylmethane (27), (-)-epigallocatechin-3-gallate (28) and resveratrol (29). Our results indicate that herbal extract CRAE has unique effects on the miRNA expression profile in HCC cells.

Prediction of the potential target genes of the selected miR-21 and miR-23a was conducted through a search of the TargetScan and PicTar databases. These genes may contribute to the development of anti-cancer drugs and cancer-targeted therapy. We found that the expression of NEK6 and SLC6A14 in MHCC97-L cells decreased after treatment with $175 \mu \mathrm{g} /$ ml CRAE. NEK6 encodes a serine or threonine kinase which mediates the initiation of mitosis. SLC6A14 is a member of the $\mathrm{Na}(+)$ and $\mathrm{Cl}(-)$-dependent neurotransmitter transporter family. Certain related target genes may play a critical role in the development of CRAE as an anti-cancer agent; this warrants further study. The tumor suppressor tropomyosin 1 (TPM1) was previously identified as a potential miR-21 target. TPM1 is an isoform of tropomyosin which belongs to a family of actin filament-binding proteins. A binding site for miR-21 was identified in the 3-UTR of the TPM2 transcript and this was shown to be necessary for miR-21-mediated translational repression (30). Another target of miR-21 that has been recently identified in breast cancer cell lines is the tumorsuppressor gene, programmed cell death-4 (PDCD4) (31). miR-21 appears to down-regulate PDCD4 at both the mRNA and protein levels, and this is at least partly responsible for some of the effects of miR-21 on cellular proliferation. In addition, miR-21 may interfere with the expression of p63 and may function as a tumor-suppressor gene in some types of cancers (32).

In conclusion, the miRNA expression profiling in the human HCC MHCC97-L cells after treatment with CRAE was determined by miRNA on-chip array and qRT-PCR. Strikingly, overexpression of miR-21 and miR-23a in the MHCC97-L cells was detected after exposure to $175 \mu \mathrm{g} / \mathrm{ml}$ of CRAE for $48 \mathrm{~h}$. Prediction of the target genes of these selected miRNAs indicated that several tumor-suppressor genes may be affected by CRAE through the altered expression of miRNAs. To the best of our knowledge, up-regulation of miRNAs, miR-21 and miR-23a, in human liver cancer cells treated with CRAE has not been previously reported in the literature. Our present findings may shed light on the novel target of CRAE in cancer therapy; however, further studies on the function of miR-21 and miR-23a, as well as their potential target genes, are warranted.

\section{Acknowledgements}

The present study was financially supported by grants from the research council of the University of Hong Kong (project code, 200907176140), the Research Grants Council (RGC) of Hong Kong SAR, China (project code, 764708M), the Pong Ding Yueng Endowment Fund for Education and Research 
in Chinese-Western Medicine (project code, 20005274) and the Hong Kong Government-Matching Grant Scheme (4th Phase, project code, 20740314). The cell line MHCC97-L was a kind gift from the Liver Cancer Institute Fudan University, Shanghai, China. The authors would like to express thanks to Dr Ka-Yu Siu, Ms. Cindy Lee, Mr. Keith Wong and Mr. Freddy Tsang for the technical support.

\section{References}

1. Cahill BA and Braccia D: Current treatment for hepatocellular carcinoma. Clin J Oncol Nurs 8: 393-399, 2004.

2. Parkin DM, Bray F, Ferlay J and Pisani P: Global cancer statistics. CA Cancer J Clin 55: 74-108, 2005.

3. Lee RC, Feinbaum RL and Ambros V: The C. Elegans heterochronic gene lin-4 encodes small RNAs with antisense complementarity to lin-14. Cell 75: 843-854, 1993.

4. Ruvkun G: Molecular biology: glimpses of a tiny RNA world. Science 294: 797-799, 2001.

5. Ji J, Shi J, Budhu A, et al: MicroRNA expression, survival, and response to interferon in liver cancer. N Engl J Med 361: 1437-1447, 2009.

6. He L, Thomson JM, Hemann MT, Hernando-Monge E, Mu D, Goodson S, Powers S, Cordon-Cardo C, Lowe SW, Hannon GJ and Hammond SM: A microRNA polycistron as a potential human oncogene. Nature 435: 828-833, 2005.

7. Chang HM and Paul But PH: Pharmacology and Applications of Chinese Materia Medica. World Scientific Publishing, Singapore, pp1061-1077, 2001.

8. Kim HY, Shin HS, Park H, Kim YC, Yun YG, Park S, Shin HJ and Kim K: In vitro inhibition of coronavirus replications by the traditionally used medicinal herbal extracts, Cimicifuga rhizoma, Meliae cortex, Coptidis rhizoma and Phellodendron cortex. J Clin Virol 41: 122-128, 2008.

9. Ye X, Feng Y, Tong Y, Ng KM, Tsao S, Lau GK, Sze C, Zhang Y, Tang J, Shen J and Kobayashi S: Hepatoprotective effects of Coptidis rhizoma aqueous extract on carbon tetrachlorideinduced acute liver hepatotoxicity in rats. J Ethnopharmacol 124: 130-136, 2009.

10. Tang J, Feng Y, Tsao S, Wang N, Curtain R and Wang Y: Berberine and Coptidis rhizoma as novel antineoplastic agents: a review of traditional use and biomedical investigations. J Ethnopharmacol 126: 5-17, 2009.

11. Tsang CM, Lau EP, Di K, Cheung PY, Hau PM, Ching YP, Wong YC, Cheung AL, Wan TS, Tong Y, Tsao SW and Feng Y: Berberine inhibits Rho GTPases and cell migration at low doses but induces G2 arrest and apoptosis at high doses in human cancer cells. Int J Mol Med 24: 131-138, 2009.

12. Bartel DP: MicroRNAs: genomics, biogenesis, mechanism, and function. Cell 116: 281-297, 2004.

13. Li Y, Zhu X, Gu J, Dong D, Yao J, Lin C, Huang K and Fei J: Anti-miR-21 oligonucleotide sensitizes leukemic K562 cells to arsenic trioxide by inducing apoptosis. Cancer Sci 101: 948-954, 2010.

14. Jiang S, Zhang HW, Lu MH, He XH, Li Y, Gu H, Liu MF and Wang ED: MicroRNA-155 functions as an oncomiR in breast cancer by targeting the suppressor of cytokine signaling 1 gene. Cancer Res 70: 3119-3127, 2010.

15. Sun Y, Bai Y, Zhang F, Wang Y, Guo Y and Guo L: miR-126 inhibits non-small cell lung cancer cell proliferation by targeting EGFL7. Biochem Biophys Res Commun 391: 1483-1489, 2010.
16. Bhattacharya R, Nicoloso M, Arvizo R, Wang E, Cortez A Rossi S, Calin GA and Mukherjee P: MiR-15a and MiR-16 control Bmi-1 expression in ovarian cancer. Cancer Res 69: 9090-9095, 2009.

17. Bhattacharyya SN, Habermacher R, Martine U, Closs EI and Filipowicz W: Relief of microRNA-mediated translational repression in human cells subjected to stress. Cell 125: 1111-1124, 2006.

18. Feng Y, Cheung KF, Wang N, Liu P, Nagamatsu T and Tong Y: Chinese medicines as a resource for liver fibrosis treatment. Chin Med 4: 16, 2009.

19. Cragg GM and Newman DJ: Plants as a source of anti-cancer agents. J Ethnopharmacol 100: 72-79, 2005.

20. Yang LQ, Singh M, Yap EH, Ng GC, Xu HX and Sim KY: In vitro response of Blastocystis hominis against traditional Chinese medicine. J Ethnopharmacol 55: 35-42, 1996.

21. Feng Y, Luo WQ and Zhu SQ: Explore new clinical application of Huanglian and corresponding compound prescriptions from their traditional use. Zhongguo Zhong Yao Za Zhi 33: 1221-1225, 2008.

22. Luo WQ, Hui SC, Chan TY and Feng Y: Inhibitory effect of water extract from golden thread (Huanglian) on leukemia L-1210 cells cultured in vitro. Pharmacologist 44: 126, 2002.

23. Gao P, Tchernyshyov I, Chang TC, Lee YS, Kita K, Ochi T, Zeller KI, De Marzo AM, van Eyk JE, Mendell JT and Dang CV: $\mathrm{c}-\mathrm{Myc}$ suppression of $\mathrm{miR}-23 \mathrm{a} / \mathrm{b}$ enhances mitochondrial glutaminase expression and glutamine metabolism. Nature 458: 762-765, 2009.

24. Yan LX, Huang XF, Shao Q, Huang MY, Deng L, Wu QL, Zeng YX and Shao JY: MicroRNA miR-21 overexpression in human breast cancer is associated with advanced clinical stage, lymph node metastasis and patient poor prognosis. RNA 14: 2348-2360, 2008.

25. Sun M, Estrov Z, Ji Y, Coombes KR, Harris DH and Kurzrock R: Curcumin (diferuloylmethane) alters the expression profiles of microRNAs in human pancreatic cancer cells. Mol Cancer Ther 7: 464-473, 2008.

26. Li Y and Sarkar FH: Down-regulation of invasion and angiogenesis-related genes identified by cDNA microarray analysis of PC3 prostate cancer cells treated with genistein. Cancer Lett 186: 157-164, 2002.

27. Garikapaty VP, Ashok BT, Tadi K, Mittelman A and Tiwari RK: 3,3'-Diindolylmethane downregulates pro-survival pathway in hormone independent prostate cancer. Biochem Biophys Res Commun 340: 718-725, 2006.

28. Katiyar SK, Afaq F, Perez A and Mukhtar H: Green tea polyphenol (-)-epigallocatechin-3-gallate treatment of human skin inhibits ultraviolet radiation-induced oxidative stress. Carcinogenesis 22: 287-294, 2001

29. Kundu JK and Surh YJ: Cancer chemopreventive and therapeutic potential of resveratrol: mechanistic perspectives. Cancer Lett 269: 243-261, 2008.

30. Zhu S, Si ML, Wu H and Mo YY: MicroRNA-21 targets the tumor suppressor gene tropomyosin 1 (TPM1). J Biol Chem 282: 14328-14336, 2007.

31. Frankel LB, Christoffersen NR, Jacobsen A, Lindow M, Krogh A and Lund AH: Programmed cell death 4 (PDCD4) is an important functional target of the microRNA miR-21 in breast cancer cells. J Biol Chem 283: 1026-1033, 2008.

32. Papagiannakopoulos T, Shapiro A and Kosik KS: MicroRNA-21 targets a network of key tumor-suppressive pathways in glioblastoma cells. Cancer Res 68: 8164-8172, 2008. 